\title{
Sovereign CDS Premiums' Reaction to Macroeconomic News: An Empirical Investigation
}

\author{
Min Lu (i), ${ }^{1}$ Michele Passariello, ${ }^{2}$ and Xing Wang $\mathbb{D}^{2}$ \\ ${ }^{1}$ Nanjing Audit University, Nanjing, China \\ ${ }^{2}$ Durham University Business School, Durham, UK \\ Correspondence should be addressed to Min Lu; lumin@nau.edu.cn
}

Received 20 February 2021; Revised 3 July 2021; Accepted 22 July 2021; Published 30 July 2021

Academic Editor: Lei Xie

Copyright (c) 2021 Min Lu et al. This is an open access article distributed under the Creative Commons Attribution License, which permits unrestricted use, distribution, and reproduction in any medium, provided the original work is properly cited.

We assess the efficiency of the sovereign credit default swap (CDS) market by investigating how sovereign CDS spreads react to macroeconomic news announcements. Contrary to the vast majority of the existing literature, one of our main findings supports the hypothesis that news announcements reduce market uncertainty and, thus, that both better- and worse-than-expected news lower CDS prices during our sample period. In addition, we find that CDS spreads respond differently to the four macroindicators across the three different regions. Our findings might help investors in these areas to interpret the surprises of macronews announcements when making decisions in CDS markets.

\section{Introduction}

Sovereign credit default swaps (CDS) are deemed to accurately capture the inherent credit risk within a country's economy. The sovereign CDS market has been under intense scrutiny in the last decade, following the European sovereign debt crisis that started in 2008 with the collapse of Iceland's banking system and then spread to other countries such as Greece and Portugal during 2009. Whether the spread of sovereign CDS can efficiently reflect the risk related to a country's economy is of great importance [1]. In this paper, we conduct an event study to assess the efficiency of the sovereign CDS market by investigating how the sovereign CDS spread reacts to four types of macroeconomic news: gross domestic product (GDP), consumer price index (CPI), unemployment rate, and consumer sentiment announcements. Our empirical study also aims to test whether news announcements increase or decrease the uncertainty of the sovereign CDS market.

Our paper fits into two streams in the literature. The first is the study of the financial markets' reactions to macro news announcements. For instance, Andersen et al. [2] investigated the incorporation of macroeconomic fundamentals into different security prices and found that the dynamics of the exchange rates are linked to fundamentals. Balduzzi et al. [3] consider the effect of 26 macroeconomic variables on the US Treasury bond prices ascertaining the significance of 17 public releases as well as an aftermath drift due to the new information. Bond prices are investigated by Beetsma et al. [4] who found that bond yield spreads are deemed to be volatile during announcement speeches with consistent spillover effects. Andritzky et al. [5], Arru et al. [6], and Kurov and Stan [7] modeled the bond volatilities in emerging markets and the US bond market. Vrugt [8] tested whether macroeconomic announcements play a role in the determination of conditional means, variances, and covariances in the stock and bond markets. The answer is affirmative, and the author also found a postannouncement drift towards the direction of the news.

The second stream focuses on the sovereign CDS spread and is relatively newer than the first stream but still includes a broad range of studies performed in the past two decades. For instance, Heinz and Sun [9] and Chebbi and Sarraj [10] investigated the variables underlying the movements of the sovereign CDS spreads focusing on the Euro area countries after the subprime mortgage financial crises. They found that the sovereign market moves from three different viewpoints: global investor sentiment proxied by the VIX index, the 
liquidity in the CDS market represented by the CDS bid-ask spreads, and a set of macroeconomic indicators such as the GDP growth rate, predicted fiscal deficit, and forecast of current account balance and public debt to GDP ratio. All these factors are highly significant in the determination of the sovereign market movements both before and after 2012 . Longstaff et al. [11] investigated the sovereign credit risk by CDS and bond yield spreads between 2007 and 2010. They found theoretical evidence of global factors, risk premiums, and investment flows accounting for movements in the sovereign credit risk more than the country-specific factors such as macroeconomic fundamentals. Narayan and Bannigidadmath [12] found that CDS spreads changes are dominated by forecasting models that use positive news as a predictor.

Our paper complements the extant macroeconomic news and sovereign CDS theoretical contributions. It additionally deepens the knowledge about the sovereign CDS premiums' behaviour. We take inspiration from related studies, yet our work differs from the previous studies in some aspects.

Specifically, instead of using straight news announcements, we focus on the way that better/worse-than-expected news (i.e., news surprise) affects sovereign CDS quotes. Better/worse-than-expected news contains a greater/smaller released value than the economic consensus. By analysing the effects of news in this manner, it is possible to test the informational efficiency of the market and the promptitude with which sovereign CDS prices incorporate new information.

Additionally, the majority of the past works including the aforementioned papers typically concentrate on the determinants of market returns or CDS spread and employ regression analysis to test the significance of multiple variables. In this paper, we employ an event study approach that allows us to evaluate not only the overall magnitude of the effect on the announcement day but also the effect in the long run. To the best of our knowledge, to date, no event study that focuses on the global sovereign CDS market and public news surprises about contingent countries' fundamentals has been performed. Therefore, we mainly base this work on few reference studies trying to advance with respect to the analytic procedures and interpretations of the economic results. Greatrex [13] conducts an event study that investigates the CDS and stock corporate markets' efficiency in absorbing corporate earnings surprises. The authors found that news has a significant impact on both markets and that CDS prices are inversely correlated with good and bad news. Furthermore, market efficiency is examined, and it is reported that both CDS and stock prices anticipate the news as confirmed by abnormal returns. Kim et al. [14] carry out an analysis based on the domestic and spillover news effect on the US, China, and the eurozone sovereign CDS market. In addition to the central focus on the international responses to domestic news, they ascertain that good news has an economic and statistically greater impact on CDS prices than bad news.

For the sake of developing a deeper understanding of what drives sovereign CDS premiums, this study aims to address 3 main research questions that are based on the conventional literature intuitions proposed by Beetsma et al. [4] and Conrad et al. [15] and go beyond them, focusing the analysis on the specific macroeconomic indicators as described in Heinz and Sun [9]:

First, we note that there is some very recent literature on the effects of news announcement from an information theoretic approach. For instance, Ehrmann et al. [16] found that release of public information may increase or decrease the uncertainty of the market, depending on how central banks reflect the news. See also Kurov and Stan [7] for empirical results on reactions of equity and the crude oil market to the fluctuations of uncertainty due to the release of macro news. Since the sovereign CDS market is supposed to capture the risk related to a country's economic environments, we hypothesise that the announcement of the four macroeconomic indicators will reduce the uncertainty and thus lower the CDS price. Second, we also check if individual variables are effective enough to produce abnormal CDS spread changes. Third, we investigated whether the reaction of the CDS market to macroeconomic fundamentals is the same across three geographic regions, namely, Europe, the Middle East, and Africa (EMEA) region, and the American and Asian Pacific countries.

The event study enables us to obtain the following interesting findings. Better-than-expected news and worsethan-expected news both lower sovereign credit default swap prices within the sample interval. This finding appears odd, and we give some explanations for this finding below. However, the magnitude of the effect does vary with reference to the event window considered. The reaction to positive surprises is valued more by market participants than negative deviations. Moreover, single macroeconomic fundamentals provoke different drifts in the credit derivative market quotations. Gross domestic product and unemployment rate announcements reflecting the current economic situation are found to be ineffective in conditioning CDS prices. In contrast, consumer price index and consumer sentiment releases have a robust effect over the estimated economic period. Macroregional factors represent a further viewpoint from which to evaluate the impact of news. The EMEA region is more receptive to negative releases, whereas American and Asian countries appear to need longer to incorporate the news with evidence of informational leaks.

Overall, we try to obtain evidence that the subprime mortgage financial crisis and the European sovereign debt crisis had a significant impact on the perception of news announcement by the market. The fact that macroeconomic fundamentals' impact on security prices is time-varying is unanimously agreed upon in the literature. Hence, it seems worthwhile to extend the past research and examine whether the effectiveness of the considered variables has substantially changed over time.

The remainder of this paper is organised as follows. The dataset and news indices are given in Section 2. The employed methodology to answer the three questions mentioned above is outlined in Section 3. Section 4 gives the main results of the event study, while Section 5 concludes the paper. 


\section{Data and Descriptive Statistics}

2.1. CDS Spread Patterns and Changes. The global sample takes into account sovereign CDS historical prices downloaded from Thomson Reuters DataStream. We select the average bid-ask quotations of sovereign CDS premiums, denominated in EUR and USD, with a 5-year maturity written on a senior debt reference obligation. This choice is because 5-year maturity assets are the most liquid and traded in the sovereign CDS market and are the dataset with continuous time observations. The number of contributors and the bid-ask spread generally represent two proxies for CDS market liquidity. Hence, the 5-year credit default swap exhibits a smaller bid-ask differential than longer maturities. The sample consists of 18 countries, representing 3 different macroregions: ten EMEA countries (France, Germany, Greece, Italy, Portugal, Spain, United Kingdom, Ukraine, Russia, and Turkey), as well as four American countries (Brazil, Colombia, Mexico, and Venezuela.), and four Asian Pacific countries (Australia, China, Indonesia, and Philippines.). The average of the daily CDS premiums is shown in Figure 1. The selection of the countries is the result of an accurate picking-up process. First, the countries have been chosen based on the availability of historical CDS prices. The second factor is the frequency of the key fundamentals' statements. For the nations in the sample, both the announced value and economic consensus of the specific macroeconomic indicator are reported. Moreover, the susceptibility to news played an important role in the determination of the series as well as the geographical location of the aforementioned states. Last, all the countries in the sample appear in the member list of the two sovereign CDS indices that we use to compute the market return proxy.

Although a large part of literature has focused on the analysis of CDS spread responsiveness to news during the subprime mortgage crisis and the subsequent months, we concentrate on the economic period (June 1, 2009, to June 1, 2016) that coincides with the European sovereign debt crisis and its consequences over the following years to date.

By examining the CDS prices at level, we can spot similar macroregional patterns within the analysed time period. EMEA region countries show a recovery trend from the subprime mortgage crisis in the first sample half and are characterised by the European sovereign debt crisis in the second half. Focusing on individual countries, Germany presents the lowest mean CDS spreads, with 25.20 basis points per annum (bps) over the analysis period, whereas Greece exhibits the highest values (2904.02 bps). American countries exhibit low volatility between 2010 and 2015 . However, these countries show an interesting downturn that began in the second half of 2015 due to a sharp depreciation of home currencies, an increase in foreign exchange market volatility, and a plunge in oil prices. Brazil, Colombia, and Mexico present a similar level of riskiness, with a mean CDS spread of $185.73 \mathrm{bps}, 152.17 \mathrm{bps}$, and $135.96 \mathrm{bps}$, respectively, whereas Venezuela stands out with an average of 2041.56 bps as it has recently experienced economic distress due to oil supply and prices. Asian countries are more tranquil. Insurance on Australian and Chinese issued debt (respectively, $51.53 \mathrm{bps}$ and $95.50 \mathrm{bps}$ as average annually paid premium) is found to be less risky than Indonesian and Philippine reference obligations (respectively, 203.79 bps and $142.90 \mathrm{bps}$ on average).

For the purpose of the analysis, following Andres et al. [17] and Bouzgarrou and Chebbi [18], we define the daily relative spread changes as

$$
\Delta \mathrm{SC}_{i, t}=\ln \left(\mathrm{SC}_{i, t}\right)-\ln \left(\mathrm{SC}_{i, t-1}\right),
$$

where $\mathrm{SC}_{i, t}$ is the level of CDS spread for country $i$ at time $t$. Descriptive statistics for $\Delta \mathrm{SC}_{i, t}$ are shown in Table 1. It is important to note that consistent with the literature $([14,19]$, among others), CDS daily relative spread changes are nonnormally distributed, are either positively or negatively skewed, and exhibit excess kurtosis.

2.2. CDS Indices. For the event study investigating abnormal change in the CDS spread, we need to obtain the normal CDS performance. For this purpose, we compute an ad hoc market return index as the normal CDS spread:

$$
I=\frac{\mathrm{i} \operatorname{Traxx} \text { SWE index }+ \text { CDX index }}{2} .
$$

So, $I$ is the average of two of the main sovereign CDS indices quoted daily by the Markit: iTraxx SOVX Western Europe (SWE) and CDX index (indices taken from Bloomberg.). The first index contains 14 of the most relevant Western European countries in the member list, and the CDX index specifically applies to emerging markets (the Markit iTraxx SOVX Western Europe index is composed of the credit default swaps written on the following countries: Austria, Belgium, Denmark, Finland, France, Germany, Ireland, Italy, Norway, Portugal, Spain, Sweden, The Netherlands, and United Kingdom. The reference entities composing the Markit CDX Index are as follows: Argentina, Brazil, Chile, China, Colombia, Indonesia, Malaysia, Mexico, Panama, Peru, South Africa, the Philippines, Turkey, Russia, and Venezuela). The reason behind this choice is motivated by the fact that with the exception of the USA and Australia, all the sample countries are listed in the member count of the indices. Hence, averaging the two indices enables us to represent the general level of normal return of the studied CDS sovereign market as a whole.

2.3. News Announcements. Although the vast majority of the literature takes into account forward-looking indicators, we assess the CDS premiums' reaction to the gross domestic product, consumer price index, unemployment rate, and consumer sentiment announcements. There are several reasons behind this choice. First, we want to test whether economic publication reflecting the current health of the economy can cause abnormal CDS spread changes in the sovereign market. Second, recalling that both CDS quotations and sovereign bond yield spreads can be used as indicators for country-specific default risk, we investigate whether the principal bond yield movers, as outlined in Goldberg and Leonard [20], can account for the movements 


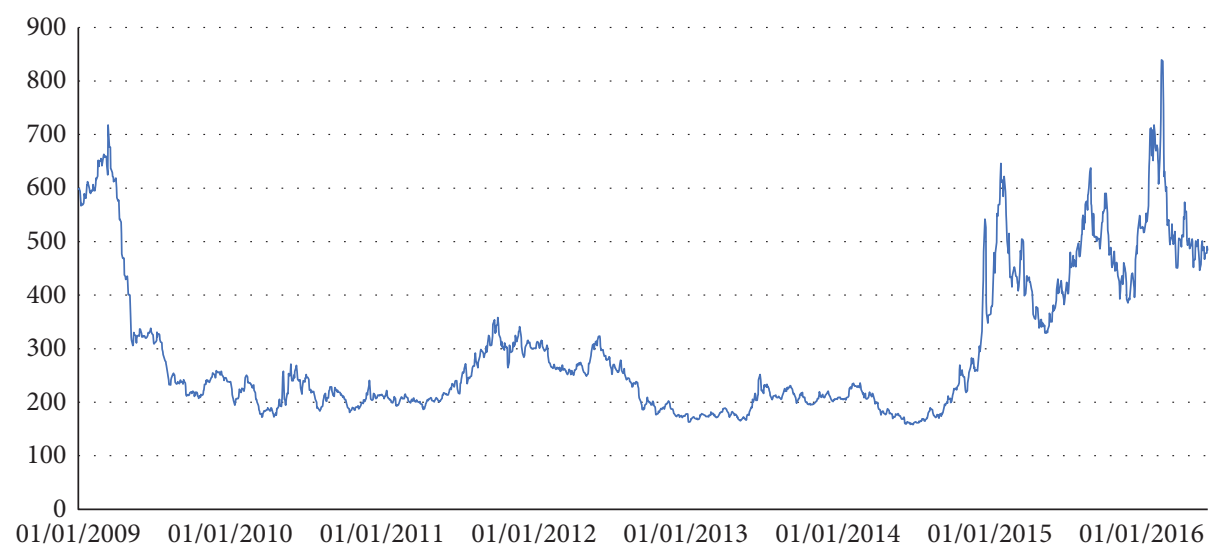

FIgURE 1: Mean daily CDS spreads for the sample countries.

TABle 1: Descriptive statistics for the CDS relative spread changes.

\begin{tabular}{|c|c|c|c|c|c|c|c|}
\hline Country/stat. & Mean & Maximum & Minimum & Std. dev. & Skewness & Kurtosis & Observations \\
\hline Australia & 51.5334 & 185.0000 & 25.0000 & 22.9668 & 2.3237 & 10.2637 & 1935 \\
\hline Brazil & 185.7271 & 500.7400 & 90.9200 & 93.2134 & 1.5661 & 4.5322 & 1935 \\
\hline China & 95.4965 & 259.5000 & 52.0000 & 32.2197 & 1.9379 & 8.2059 & 1935 \\
\hline Colombia & 152.1739 & 499.1804 & 73.8500 & 68.8704 & 2.1985 & 8.9345 & 1935 \\
\hline France & 50.8484 & 171.5600 & 14.0060 & 33.0462 & 1.3910 & 4.2849 & 1935 \\
\hline Germany & 25.2047 & 92.5000 & 6.6400 & 16.8817 & 1.1769 & 4.0890 & 1935 \\
\hline Greece & 2904.0200 & 26466.1700 & 102.9000 & 4565.8880 & 2.9355 & 12.5862 & 1935 \\
\hline Indonesia & 203.7914 & 700.0000 & 124.7800 & 96.2232 & 3.2830 & 14.6363 & 1935 \\
\hline Italy & 166.5527 & 498.6599 & 48.0000 & 102.1450 & 1.4038 & 4.1151 & 1935 \\
\hline Mexico & 135.9627 & 491.6130 & 64.1700 & 60.8877 & 2.8531 & 13.1588 & 1935 \\
\hline Philippines & 142.9045 & 485.0000 & 80.4000 & 64.6305 & 2.5458 & 10.9291 & 1935 \\
\hline Portugal & 359.4365 & 1521.4500 & 37.0000 & 321.3420 & 1.4492 & 4.0329 & 1935 \\
\hline Russia & 227.9381 & 793.2000 & 105.7100 & 122.1865 & 2.2847 & 9.3000 & 1935 \\
\hline Spain & 160.7141 & 492.0698 & 45.4200 & 101.5039 & 0.9712 & 3.1203 & 1935 \\
\hline Turkey & 196.7231 & 515.1567 & 99.9160 & 62.7601 & 1.8561 & 8.7117 & 1935 \\
\hline UK & 47.9505 & 165.0000 & 11.6600 & 27.3410 & 1.1637 & 4.9223 & 1935 \\
\hline Ukraine & 1231.7000 & 8943.8200 & 409.1700 & 987.3895 & 2.4701 & 10.4437 & 1935 \\
\hline Venezuela & 2041.5590 & 10995.6700 & 571.4189 & 1953.1060 & 1.7593 & 5.0619 & 1935 \\
\hline
\end{tabular}

in the national CDS market. Third, as explained by the European Commission in the "Key Economic Indicators" report, the variables represent four different key macroeconomic indicators. Whereas GDP and CPI are the most relevant indicators for the national output and prices, unemployment rate and consumer sentiment are proxies for the labour market and private consumption. We exclude the announcements with a lower value than $60 \%$ in the Bloomberg relevance index (the Bloomberg relevance index shows the country-related percentage of importance given to a specific news announcement). According to the employed methodology, we are only concerned about the specific variable's releasing date, expectation, and realisation.

To overcome the problem of different units of measurement among the variables and facilitate meaningful comparisons, we apply the approach in Balduzzi et al. [3] and Andersen et al. [2], which computes standardised news as follows:

$$
S_{k, t}=\frac{A_{k, t}-E_{k, t} \mid \Omega_{t-1}}{\sigma_{k}},
$$

where $S_{k, t}$ is the standardised news value of the indicator $k$ at time $t, A_{k, t}$ is the actual and unrevised announcement of the indicator $k$ at time $t, E_{k, t}$ is the Bloomberg survey median for the release of indicator $k$ at time $t$ used as the expected value (Vrugt [8] suggests that the economic consensus is usually accurate as it is computed through a transparent process. The expectations are collected through surveys and it is easily possible to differentiate the analysts' individual perspectives. Once the predicted values are gathered, the median of the sample will represent what it is known as "market economic consensus" for a particular variable.) based on information available $\Omega_{t-1}$ prior to the releases of the indicator, and $\sigma_{k}$ is the standard deviation of $\left(A_{k, t}-E_{k, t}\right)$ over the sample period.

To clarify the news standardisation procedure, consider an example where $k=$ GDP. On September 28, 2011, the quarterly announced French GDP year-over-year (YoY) value was $A_{k, t}=0.017$. This observation compared to the expected economic consensus $E_{k, t}=0.016$ based on the public information gives a differential of 0.001 . Considering that the differential is positive, we can interpret it as a release 
of positive surprise. Therefore, we can categorise it as positive news. Considering that the computed sample standard deviation is $\sigma_{k}=0.00064$, we obtain $S_{k, t}=1.56$. As another example, we can compute the standardised German monthly unemployment rate news published on October 27, 2010, which is $S_{k, t}=1.52$. Since a greater unemployment rate than the economic forecast indicates a negative outlook, we can interpret this result as negative news.

These numerical examples help to provide an overview of how we categorise the announced value. The next step in our methodology is the determination of a threshold that represents a delimiting point in the computation of the positive, negative, and no news indices. Since many studies such as that of Greatrex [13] use a threshold of $\pm 2.5 \%$, which is adapted to the specific conducted analysis, we set this value at \pm 0.455 . We compute this ad hoc delimiter because the absolute value of the range of positive standardised news goes from 0 to 3.46 , whereas that for negative news goes from 0 to 4.69. Therefore, we want to create indices that have as balanced a number of observations as possible in order to avoid biasing our estimation because of a disproportionate news dataset (if we use the same delimiters as Greatrex [13], we will have a very unbalanced pool of good news and bad news).

The first index takes into account the statements in which the released value overperforms the expectation. Therefore, we refer to this index as the "good" or "better than expected" news index. Mathematically, we only count standardised surprise values greater than 0.455 . Economically, we include greater than expected GDP and consumer confidence values and smaller than expected CPI and unemployment rate observations. In contrast, we estimate a "bad" or "worse than expected" news index using lower than expected GDP and consumer confidence value as well as greater than expected CPI and unemployment rate. In this case, the delimiter is the ad hoc computed value -0.455 . As stated above, this specific value is not taken from the literature. Hence, we reasonably introduce an alternative approach in order to check if it will lead to additional economically significant results. The better-than-expected news index comprises 970 announcements, whereas 775 releases compose the worse-than-expected news index. All the remaining announcements that are not part of the aforementioned indices are labelled "no news" because of a lack of effectiveness on the CDS spreads. These values are not taken into account in the analysis.

Tables 2 and 3 show the news announcements for each country grouped by the respective macroregions.

\section{Methodology}

The methodology that we employ to test the effects of macroeconomic announcements on the sovereign CDS prices is an event study that aims to measure the impact of an event on financial asset prices or firm's value. The first task in an event study is the determination of the occurrence to investigate over a predetermined period known as the event window. Consistent with Greatrex [13], the main event window $[-1 ; 1]$ starts one trading day before the event date and ends on the subsequent day. Additionally, we extend the event window $[-20 ; 20]$ to 20 trading days before and after the event date. The usefulness of a very short window can be identified from the fact that given the informational rationality of the market, security prices will reflect the new events immediately. Moreover, it is possible to evaluate the investor's reaction after the market closes. A longer observation interval will allow us to test the efficiency of the CDS sovereign market through the detection of information leaks, nonimmediate effects, and premiums drifts.

The estimation window starts 100 trading days (we assume that 100 trading days before the announcement represent a long enough time interval to estimate the normal performance without the price pattern being affected by any event effect. The estimation window stops 21 trading days prior the release day in order not to overlap with the preannouncement interval) before the event date and all of the relevant dates are represented in Figure 2.

The estimation window goes from 100 trading days to 21 days before the event date. A longer window takes into account 20 trading days before and after the announcement, whereas a shorter window only focuses on 3 trading days around the release day.

The next step in the event study procedure is the calculation of the normal performance of the sovereign CDS. This is a fundamental part of the analysis and consists of simulating what the CDS price path would have been without the impact of the event. Many different approaches for the computation of the normal performance have been introduced in the literature, and we adopt the market model cited in MacKinlay [21]. It first uses the data from the estimation period to regress the actual CDS spread changes $\Delta \mathrm{SC}_{i, t}$ on a constant and the market index premiums changes $\Delta I_{t}$, where $I_{t}$ is defined as in (2):

$$
\Delta \mathrm{SC}_{i, t}=\alpha_{i}+\beta \Delta I_{t}+\varepsilon_{i, t},
$$

where $\varepsilon_{i, t}$ is a homoscedastic disturbance term with zero mean. In this case, we should not be concerned about the overlapping effect between the different countries because the normal performance is estimated independently for each state.

Once the intercept and the beta coefficient are estimated, we calculate the abnormal spread changes $\Delta \mathrm{ASC}_{i, t}$ for each announcement as

$$
\Delta \mathrm{ASC}_{i, t}=\Delta \mathrm{SC}_{i, t}-\widehat{\alpha}_{i}-\widehat{\beta} \Delta I_{t} .
$$

The last step consists of the calculation of the cumulative abnormal spread changes ( $\triangle$ CASC) of country $i$, which corresponds to the sum of the $\Delta \mathrm{ASC}_{i, t}$ within the event window:

$$
\Delta \mathrm{CASC}_{i}=\sum_{t=1}^{T} \Delta \mathrm{ASC}_{i, t} .
$$

Since there are 18 countries in the sample, we compute $\triangle \mathrm{CASC}$ for each country and then the average value. By doing so, we estimate the cumulative average (in Sections 4.1 and 4.2 , we take the average of all of the countries in our 
TABLE 2: Number of announcements for each EMEA country.

\begin{tabular}{|c|c|c|c|c|c|}
\hline \multicolumn{6}{|c|}{ Europe, Middle East, and Africa } \\
\hline Variable & Frequency & N. events & Variable & Frequency & N. events \\
\hline \multicolumn{3}{|c|}{ France } & \multicolumn{3}{|c|}{ Russia } \\
\hline GDP YoY & Quarterly & $25(4,6,15)$ & GDP YoY & Quarterly & $7(3,0,4)$ \\
\hline CPI YoY & Quarterly & $82(38,17,27)$ & CPI YoY & Quarterly & $72(15,8,49)$ \\
\hline UR & Monthly & $25(11,6,8)$ & UR & Monthly & $75(30,10,35)$ \\
\hline CS & Monthly & $146(61,49,36)$ & CS & Monthly & $0(0,0,0)$ \\
\hline \multicolumn{3}{|c|}{ Germany } & \multicolumn{3}{|c|}{ Spain } \\
\hline GDP YoY & Quarterly & $26(0,0,26)$ & GDP YoY & Quarterly & $24(4,4,16)$ \\
\hline CPI YoY & Quarterly & $78(1,11,66)$ & CPI YoY & Quarterly & $77(2,14,61)$ \\
\hline UR & Monthly & $78(23,8,47)$ & UR & Monthly & $26(6,7,13)$ \\
\hline CS & Monthly & $178(60,47,71)$ & CS & Monthly & $0(0,0,0)$ \\
\hline \multicolumn{3}{|c|}{ Greece } & \multicolumn{3}{|c|}{ Turkey } \\
\hline GDP YoY & Quarterly & $2(1,1,0)$ & GDP YoY & Quarterly & $25(13,5,7)$ \\
\hline CPI YoY & Quarterly & $12(3,5,4)$ & CPI YoY & Quarterly & $77(23,28,26)$ \\
\hline UR & Monthly & $48(16,9,23)$ & UR & Monthly & $51(18,15,18)$ \\
\hline CS & Monthly & $0(0,0,0)$ & $\mathrm{CS}$ & Monthly & $7(3,1,3)$ \\
\hline \multicolumn{3}{|c|}{ Italy } & \multicolumn{3}{|c|}{ United Kingdom } \\
\hline GDP YoY & Quarterly & $26(8,12,6)$ & GDP YoY & Quarterly & $77(17,31,29)$ \\
\hline CPI YoY & Quarterly & $76(12,14,50)$ & CPI YoY & Quarterly & $77(25,23,29)$ \\
\hline UR & Monthly & $25(10,5,10)$ & UR & Monthly & $77(29,16,32)$ \\
\hline CS & Monthly & $168(59,43,66)$ & CS & Monthly & $89(26,27,36)$ \\
\hline \multicolumn{3}{|c|}{ Portugal } & \multicolumn{3}{|c|}{ Ukraine } \\
\hline GDP YoY & Quarterly & $22(7,6,9)$ & GDP YoY & Quarterly & $0(0,0,0)$ \\
\hline CPI YoY & Quarterly & $46(15,11,20)$ & CPI YoY & Quarterly & $75(11,14,50)$ \\
\hline UR & Monthly & $0(0,0,0)$ & UR & Monthly & $0(0,0,0)$ \\
\hline $\mathrm{CS}$ & Monthly & $0(0,0,0)$ & CS & Monthly & $0(0,0,0)$ \\
\hline
\end{tabular}

This table shows the macroeconomic fundamentals announcements for each EMEA country from June 1, 2009, to June 1, 2016. We report the name of the variable, the frequency of the announcement, and the number of events. In the brackets, we express the number of better-than-expected news announcements, the number of worse-than-expected news announcements, and the announcements correctly anticipated by the market consensus.

Table 3: Number of announcements for each American and Asian Pacific country.

\begin{tabular}{|c|c|c|c|c|c|}
\hline \multicolumn{3}{|c|}{ Americas } & \multicolumn{3}{|c|}{ Asia Pacific } \\
\hline Variable & Frequency & N. events & Variable & Frequency & N. events \\
\hline \multicolumn{3}{|c|}{ Brazil } & \multicolumn{3}{|c|}{ Australia } \\
\hline GDP YoY & Quarterly & $26(7,12,7)$ & GDP YoY & Quarterly & $26(12,5,9)$ \\
\hline CPI YoY & Quarterly & $77(18,20,39)$ & CPI YoY & Quarterly & $26(10,5,11)$ \\
\hline UR & Monthly & $72(32,15,25)$ & UR & Monthly & $77(37,15,25)$ \\
\hline CS & Monthly & $5(2,2,1)$ & CS & Monthly & $0(0,0,0)$ \\
\hline \multicolumn{3}{|c|}{ Colombia } & \multicolumn{3}{|c|}{ China } \\
\hline GDP YoY & Quarterly & $25(8,4,13)$ & GDP YoY & Quarterly & $26(15,6,5)$ \\
\hline CPI YoY & Quarterly & $77(22,23,32)$ & CPI YoY & Quarterly & $77(29,29,19)$ \\
\hline UR & Monthly & $77(22,22,33)$ & UR & Monthly & $0(0,0,0)$ \\
\hline $\mathrm{CS}$ & Monthly & $30(8,12,10)$ & $\mathrm{CS}$ & Monthly & $81(15,23,43)$ \\
\hline \multicolumn{3}{|c|}{ Mexico } & \multicolumn{3}{|c|}{ Indonesia } \\
\hline GDP YoY & Quarterly & $26(6,9,11)$ & GDP YoY & Quarterly & $26(7,5,14)$ \\
\hline CPI YoY & Quarterly & $76(34,23,19)$ & CPI YoY & Quarterly & $78(31,20,27)$ \\
\hline UR & Monthly & $77(28,25,24)$ & UR & Monthly & $0(0,0,0)$ \\
\hline CS & Monthly & $89(22,31,36)$ & CS & Monthly & $0(0,0,0)$ \\
\hline \multicolumn{3}{|c|}{ Venezuela } & \multicolumn{3}{|c|}{ Philippines } \\
\hline GDP YoY & Quarterly & $19(7,4,8)$ & GDP YoY & Quarterly & $26(10,6,10)$ \\
\hline CPI YoY & Quarterly & $42(10,13,19)$ & CPI YoY & Quarterly & $77(33,12,32)$ \\
\hline UR & Monthly & $1(1,0,0)$ & UR & Monthly & $0(0,0,0)$ \\
\hline $\mathrm{CS}$ & Monthly & $0(0,0,0)$ & CS & Monthly & $0(0,0,0)$ \\
\hline
\end{tabular}

This table shows the macroeconomic fundamentals announcements for each American and Asian Pacific country from June 1, 2009 , to June 1, 2016. 


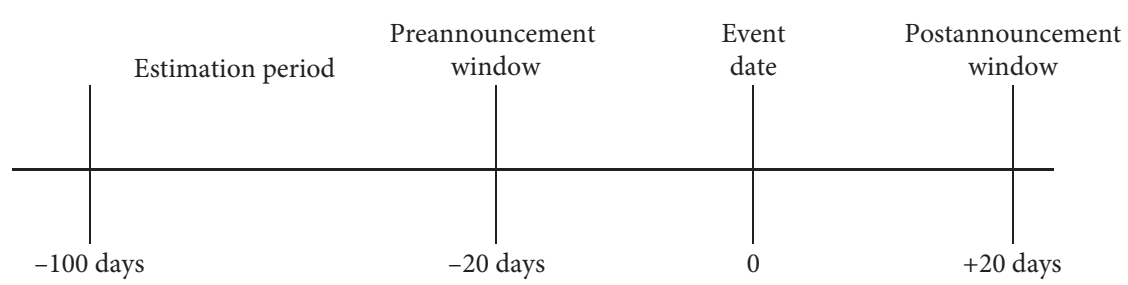

FIgUre 2: Event study timeline.

sample to investigate the overall reaction of the CDS spread to macro news, while in Section 4.3, we take the average in each region so that we can analyse the differences in the reaction between the three regions) abnormal spread changes (CAASC):

$$
\mathrm{CAASC}=\frac{1}{n} \sum_{i=1}^{n} \Delta \mathrm{CASC}_{i} .
$$

Once the CAASC values are determined, we use different test statistics to verify the significance of the changes. Specifically, we test $H_{0}$ : CAASC $=0$ (i.e., the reaction is not significant) against the alternative $H_{1}$ : CAASC $\neq 0$ (i.e., the reaction is significant). Therefore, we investigate whether the CDS prices experience a significant variation due to a precise event against a lack of a substantial reaction in the premiums path.

The vast majority of the literature solely conducts a $t$-test. However, further enquiries may be employed (the $t$-test is very straightforward but is subject to cross-sectional correlation and volatility changes, while the Patell test and BMP test are both not influenced by the distribution of ASCs in the event window and account for serial correlation and event-induced volatility but appear to be generally prone to cross-sectional correlation bias. Nonparametric tests do not require any specific distribution of the spread changes and may thus be more powerful than parametric tests. Nevertheless, the literature explains that the generalised sign test accounts for skewness in the return distribution. Therefore, Andres et al. [17] outlined the process steps for a robustness check, based on Barber et al. [22] and Hull et al. [19]. The procedure allows us to correct for the distribution skewness and appears to lead to an improvement in the test efficiency). The adjusted Patell test and Bohemer, Musumeci, and Poulsen (BMP) test are used in our study. These statistics provide better estimates when the variables are normally distributed. In fact, CDS spread changes are positively or negatively skewed and have excess kurtosis. Therefore, to check the validity of the results, we include nonparametric tests. The skewed adjusted test and generalised sign test are components of those test families. A robustness check consisting of the bootstrap methodology completes the result verification. Data-driven nonparametric methods can also avoid the potential problem of heterogeneity across countries.

\section{Empirical Results}

In light of the research questions, we initially test the CDS prices responses from June 1, 2009, to June 1, 2016, within the main event windows $[-20 ; 20],[-1 ; 1]$ and event date $[0$; $0]$. Better/worse-than-expected news indices are assessed separately, which is one of our main contributions. In Tables 4-20, test statistics are reported, while we only consider those significant results that are confirmed by at least three out of six test statistics and at least one parametric and nonparametric test. All the results undergo a robustness check that is performed through a bootstrap process with 1000 resamples, and the bootstrapped $p$ value is reported in the last column of each table.

4.1. Reaction to Contingent News Announcements. Table 4 shows that if we take the whole sample into account, better-than-expected news lowers the CDS spreads. This result is consistent with previous studies such as Greatrex [13], Heinz and Sun [9], and Kim et al. [14]. More specifically, the magnitude of the cumulative average decrease is 236 basis points within a 3 -day window around the event date. The statistical insignificance of the abnormal premium changes on the release day makes us suspect that the sovereign CDS market is characterised by information incorporation inefficiencies. Therefore, we extend the analysis to the worse-than-expected news index.

Whereas the impact of good news is fully aligned with the literature, the investigation of bad news effects leads to the most interesting contribution of our research work, as shown in Table 5. Even though the vast majority of the literature point towards the opposite intuition, in the investigated sample that proxies for the CDS market as a whole, we observe that worse-than-expected news lowers CDS spreads. These findings suggest that the risk perception decreases even when the released macroeconomic variables underperform the analysts' forecasts. The effect of the impact is small and not significant within the main event window ( $-188 \mathrm{bps})$. However, it is considerable and highly significant on the event date $(-228 \mathrm{bps})$. The last result is consistent with Heinz and Sun [9] who found that CDS spreads tend to react immediately to new information. Indeed, the news component incorporation occurs instantly.

For the 41-day event window, both of the news indices provoke abnormal patterns. The effect is substantial and negative, indicating that the sovereign CDS market fails the efficiency test. The prices' underreaction appears to be a serious challenge to the efficient market hypothesis because a price downward drift means that the market is incapable of translating information into prices. Nevertheless, the reduced effect of the news on CDS prices indicates a new feature of the quotations' behaviour. It is also worth noting that if we look at the frequency of the positive and negative announcements over the reference years, there is an overall predominance of releases that beat the forecast expectations. 
TABLE 4: Impact of better-than-expected news for all countries.

\begin{tabular}{|c|c|c|c|c|c|c|c|}
\hline \multirow{2}{*}{$\begin{array}{l}\text { All countries } \\
\text { Test/event window }\end{array}$} & \multicolumn{7}{|c|}{ Better-than-expected news } \\
\hline & Caasc & $t$-test & Adjusted Patell test & BMP test & Generalized sign test & Skewed-adjusted test & Bootstrap $p$ value \\
\hline$[-20 ; 20]$ & $-398 \mathrm{bps}$ & -0.87 & -0.16 & -0.32 & $5.11^{* * *}$ & $3.39^{* * *}$ & $0.00^{* * *}$ \\
\hline$[-1 ; 1]$ & -236 bps & $-1.91^{*}$ & -0.84 & -0.92 & -0.88 & $2.15^{* *}$ & $0.046^{* *}$ \\
\hline$[0 ; 0]$ & -31 bps & -0.43 & -0.15 & -0.13 & -1.50 & $2.54^{* *}$ & $0.018^{* *}$ \\
\hline
\end{tabular}

The symbols, ${ }^{* * *},{ }^{* *}$, and ${ }^{*}$ correspond, respectively, to a significance level of $1 \%, 5 \%$, and $10 \%$.

TABLE 5: Impact of worse-than-expected news for all countries.

\begin{tabular}{|c|c|c|c|c|c|c|c|}
\hline \multirow{2}{*}{$\begin{array}{l}\text { All countries } \\
\text { Test/event window }\end{array}$} & \multicolumn{7}{|c|}{ Worse-than-expected news } \\
\hline & Caasc & $t$-test & Adjusted Patell test & BMP test & Generalized sign test & Skewed-adjusted test & Bootstrap $p$ value \\
\hline$[-20 ; 20]$ & -1053 bps & $-2.04^{* *}$ & -0.83 & -1.57 & $4.93^{* *}$ & $3.92^{* * *}$ & $0.00^{* * *}$ \\
\hline$[-1 ; 1]$ & -188 bps & -1.34 & -0.88 & -0.96 & 0.71 & $1.86^{*}$ & 0.83 \\
\hline$[0 ; 0]$ & $-228 \mathrm{bps}$ & $-2.83^{*}$ & $-2.24^{* *}$ & $-2.13^{* *}$ & $-2.38^{* *}$ & -0.50 & 0.64 \\
\hline
\end{tabular}

The symbols ${ }^{* *},{ }^{* *}$, and ${ }^{*}$ correspond, respectively, to a significance level of $1 \%, 5 \%$, and $10 \%$.

Globally, the sample allows ascertaining that the sovereign risk market tends to value new information about macroeconomic fundamentals positively. However, other variables may influence the direction of the drift.

Moreover, a Wilcoxon signed rank test (Wilcoxon [23] shows that the differential (The difference in the effect is computed by subtracting the absolute value of the cumulative abnormal spread changes for worse-than-expected news from the absolute value of the cumulative abnormal spread changes for better-than-expected news.) in the effect of the better- and worse-than-expected news is statistically different from zero (see Table 6). Hence, it is possible to conclude that the market values positive surprises more strongly than negative surprises within the estimated interval.

\subsection{Reaction to Individual Fundamental News} Announcements. Since the aforementioned results capture new features of the behaviour of sovereign CDS premiums, it appears worthwhile to deepen the knowledge and determine the effects of the individual fundamentals. This approach will help attribute the price patterns to the specific variables. For the sake of the analysing individual variables, we create GDP, CPI, unemployment rate, and consumer sentiment news indices for both good and bad realisation/expectation surprises, and we cross-test them over the entire sample. The numerical test results and discussion are given in the 8 tables from Table 7 to Table 14, for the four macroeconomic indicators, respectively.

4.2.1. Gross Domestic Product. The effect of better-thanexpected GDP news does not provoke any abnormal spread reaction on the 18 countries in the sample. The overall change is in line with the literature, as it is found that good news lowers CDS premiums both in the short $[-1 ; 1]$ and longer $[-20 ; 20]$ event window.

Similarly, sovereign risk indicators do not appear to instantaneously abnormally react to worse-than-expected GDP news. Additionally, CDS prices show the tendency of
TABLE 6: Wilcoxon singed rank test results.

\begin{tabular}{lc}
\hline All countries & Wilcoxon signed rank test \\
\hline Event window $[-1 ; 1]$ & \\
CAASCs bad news & $188 \mathrm{bps}$ \\
CAASCs good news & $236 \mathrm{bps}$ \\
\hline Difference in effects & $48 \mathrm{bps}$ \\
& $(0.025)^{* *}$ \\
\hline
\end{tabular}

The symbol ** corresponds, respectively, to a significance level of $5 \%$.

not incorporating the national output communications very quickly. In reality, the fact that current GDP announcements are not effective enough to cause a substantial reaction in the main event window should not be surprising. Goldberg and Leonard [20] and Heinz and Sun [9] agree that the major effect on CDS spreads is due to the forward-looking indicators that reflect the future domestic health of the economy. Nevertheless, the anticipation and postdrift effects represent an advance in CDS price behaviour analysis.

4.2.2. Consumer Price Index. CPI is another macroeconomic fundamental that is not conventionally considered to be forward-looking. Interestingly, both good and bad news indices provoke a consistent change in the CDS spreads in the long run, and only better-than-expected information induces an abnormal reaction in the sovereign CDS market. An interesting feature is derived from the event study results. Although very significant, positive surprises cumulatively lower CDS premiums by 875 basis points in the 41-day reference interval and increase them by 324 basis points in the 3-day window. A potential explanation, combined with the stronger impact of more powerful determinants and spillover effects, is the fact that new information regarding inflation is often difficult to interpret. Indeed, an average hike in the price levels can be positively evaluated by deflationary countries and can counteract a plunge in prices. Hence, due to our variable sample, we can impute the increasing effect of CPI news to the specific country-related domestic conditions. 
TABLe 7: Impact of better-than-expected GDP news.

\begin{tabular}{|c|c|c|c|c|c|c|c|}
\hline \multirow{2}{*}{$\begin{array}{l}\text { All countries } \\
\text { Test/event window }\end{array}$} & \multicolumn{7}{|c|}{ Better-than-expected GDP news } \\
\hline & Caasc & $t$-test & Adjusted Patell test & BMP test & Generalized sign test & Skewed-adjusted test & Bootstrap $p$ value \\
\hline$[-20 ; 20]$ & $-763 \mathrm{bps}$ & -0.68 & -0.29 & -0.63 & 1.30 & 0.33 & 0.75 \\
\hline$[-1 ; 1]$ & +73 bps & 0.24 & 0.20 & 0.20 & 0.87 & 1.43 & 0.18 \\
\hline$[0 ; 0]$ & $+56 \mathrm{bps}$ & 0.32 & 0.46 & 0.47 & -0.19 & 1.31 & 0.27 \\
\hline
\end{tabular}

TABLE 8: Impact of worse-than-expected GDP news.

\begin{tabular}{lccccccc}
\hline All countries & & \multicolumn{5}{c}{ Worse-than-expected GDP news } \\
Test/event window & Caasc & $t$-test & Adjusted Patell test & BMP test & Generalized sign test & Skewed-adjusted test & Bootstrap $p$ value \\
\hline$[-20 ; 20]$ & $-1033 \mathrm{bps}$ & -0.75 & -0.60 & -1.53 & $2.51^{* *}$ & 1.41 & 0.23 \\
{$[-1 ; 1]$} & $+179 \mathrm{bps}$ & 0.48 & 0.94 & 0.99 & 0.03 & $2.09^{* *}$ & $0.08^{*}$ \\
{$[0 ; 0]$} & $-237 \mathrm{bps}$ & -1.10 & -0.92 & -1.21 & $-1.77^{*}$ & -0.55 & 0.62 \\
\hline
\end{tabular}

The symbols ${ }^{* *}$ and ${ }^{*}$ correspond, respectively, to a significance level of $5 \%$ and $10 \%$.

TABLE 9: Better-than-expected CPI news impact event study results.

\begin{tabular}{|c|c|c|c|c|c|c|c|}
\hline \multirow{2}{*}{$\begin{array}{l}\text { All countries } \\
\text { Test/event window }\end{array}$} & \multicolumn{7}{|c|}{ Better-than-expected CPI news } \\
\hline & Caasc & $t$-test & Adjusted Patell test & BMP test & Generalized sign test & Skewed-adjusted test & Bootstrap $p$ value \\
\hline$[-20 ; 20]$ & $-857 \mathrm{bps}$ & -1.10 & 0.02 & 0.05 & $3.38^{* * *}$ & $2.16^{* *}$ & $0.04^{* *}$ \\
\hline$[-1 ; 1]$ & $+324 \mathrm{bps}$ & 1.54 & $2.33^{* *}$ & $2.10^{* *}$ & $3.94^{* * *}$ & $4.08^{* * *}$ & $0.00^{* * *}$ \\
\hline$[0 ; 0]$ & +20 bps & 0.17 & 0.74 & 0.55 & 0.68 & 1.38 & 0.19 \\
\hline
\end{tabular}

The symbols ${ }^{* * *}$ and ${ }^{* *}$ correspond, respectively, to a significance level of $1 \%$ and $5 \%$.

TABLE 10: Worse-than-expected CPI news impact event study results.

\begin{tabular}{|c|c|c|c|c|c|c|c|}
\hline \multirow{2}{*}{$\begin{array}{l}\text { All countries } \\
\text { Test/event window }\end{array}$} & \multicolumn{7}{|c|}{ Worse-than-expected CPI news } \\
\hline & Caasc & $t$-test & Adjusted Patell test & BMP test & Generalized sign test & Skewed-adjusted test & Bootstrap $p$ value \\
\hline$[-20 ; 20]$ & -1448 bps & -1.59 & -0.79 & $-1.65^{*}$ & $2.56^{* *}$ & 1.39 & 0.16 \\
\hline$[-1 ; 1]$ & $+137 \mathrm{bps}$ & 0.55 & 1.28 & 1.11 & $2.56^{* *}$ & $2.04^{* *}$ & $0.04^{* *}$ \\
\hline$[0 ; 0]$ & $+9 \mathrm{bps}$ & 0.06 & 0.84 & 0.64 & 1.58 & 1.26 & 0.21 \\
\hline
\end{tabular}

The symbols ${ }^{* *}$ and ${ }^{*}$ correspond, respectively, to a significance level of $5 \%$ and $10 \%$.

TABLE 11: Better-than-expected UR news impact event study results.

\begin{tabular}{|c|c|c|c|c|c|c|c|}
\hline \multirow{2}{*}{$\begin{array}{l}\text { All countries } \\
\text { Test/event window }\end{array}$} & \multicolumn{7}{|c|}{ Better-than-expected UR news } \\
\hline & Caasc & $t$-test & Adjusted Patell test & BMP test & Generalized sign test & Skewed-adjusted test & Bootstrap $p$ value \\
\hline$[-20 ; 20]$ & $-903 \mathrm{bps}$ & -1.11 & -0.43 & -0.80 & $2.20^{* *}$ & 1.49 & 0.16 \\
\hline$[-1 ; 1]$ & $-204 \mathrm{bps}$ & -0.93 & -0.49 & -0.55 & -1.21 & 0.97 & 0.38 \\
\hline$[0 ; 0]$ & $+26 \mathrm{bps}$ & 0.21 & 0.57 & 0.60 & 0.36 & $2.03^{* *}$ & $0.07^{*}$ \\
\hline
\end{tabular}

The symbols ${ }^{* *}$ and * correspond, respectively, to a significance level of $5 \%$ and $10 \%$.

TABLE 12: Worse-than-expected UR news impact event study results.

\begin{tabular}{lccccccc}
\hline $\begin{array}{l}\text { All countries } \\
\text { Test/event window }\end{array}$ & Caasc & $t$-test & Adjusted Patell test & BMP test & Generalized sign test & Skewed-adjusted test & Bootstrap $p$ value \\
\hline$[-20 ; 20]$ & $-539 \mathrm{bps}$ & -0.52 & 0.20 & 0.38 & $2.74^{* * *}$ & 1.46 & 0.16 \\
{$[-1 ; 1]$} & $-133 \mathrm{bps}$ & -0.47 & -0.43 & -0.51 & 0.37 & $1.96^{* *}$ & $0.09^{*}$ \\
{$[0 ; 0]$} & $-55 \mathrm{bps}$ & -0.34 & -0.77 & -0.90 & 0.37 & 1.02 & 0.42 \\
\hline
\end{tabular}

The symbols ${ }^{* * *},{ }^{* *}$, and ${ }^{*}$ correspond, respectively, to a significance level of $1 \%, 5 \%$, and $10 \%$. 
TABLE 13: Impact of better-than-expected CS news.

\begin{tabular}{|c|c|c|c|c|c|c|c|}
\hline \multirow{2}{*}{$\begin{array}{l}\text { All countries } \\
\text { Test/event window }\end{array}$} & \multicolumn{7}{|c|}{ Better-than-expected CS news } \\
\hline & Caasc & $t$-test & Adjusted Patell test & BMP test & Generalized sign test & Skewed-adjusted test & Bootstrap $p$ value \\
\hline$[-20 ; 20]$ & $+446 \mathrm{bps}$ & 0.42 & 0.96 & $1.80^{*}$ & $3.85^{* * *}$ & $2.56^{* *}$ & $0.01^{* *}$ \\
\hline$[-1 ; 1]$ & $-193 \mathrm{bps}$ & -0.67 & -0.35 & -0.49 & $-2.39^{* *}$ & $2.93^{* * *}$ & $0.01^{* *}$ \\
\hline$[2 ; 20]$ & $+278 \mathrm{bps}$ & 0.38 & 0.84 & $1.75^{*}$ & $4.42^{* * *}$ & $1.71^{*}$ & 0.11 \\
\hline$[0 ; 0]$ & -34 bps & -0.21 & -0.65 & -0.96 & $-2.82^{* * *}$ & $1.86^{*}$ & 0.31 \\
\hline
\end{tabular}

The symbols ${ }^{* * *},{ }^{* *}$, and ${ }^{*}$ correspond, respectively, to a significance level of $1 \%, 5 \%$, and $10 \%$.

TABLE 14: Impact of worse-than-expected CS news.

\begin{tabular}{|c|c|c|c|c|c|c|c|}
\hline \multirow{2}{*}{$\begin{array}{l}\text { All countries } \\
\text { Test/event window }\end{array}$} & \multicolumn{7}{|c|}{ Worse-than-expected CS news } \\
\hline & Caasc & $t$-test & Adjusted Patell test & BMP test & Generalized sign test & Skewed-adjusted test & Bootstrap $p$ value \\
\hline$[-20 ; 20]$ & $-910 \mathrm{bps}$ & -0.88 & -0.25 & -0.43 & $2.38^{* *}$ & 1.28 & 0.21 \\
\hline$[-1 ; 1]$ & -341 bps & -1.22 & -1.56 & $-2.18^{* *}$ & -0.69 & 1.48 & 0.20 \\
\hline$[0 ; 0]$ & $-234 \mathrm{bps}$ & $-1.71^{*}$ & $-1.69^{*}$ & $-2.57^{* * *}$ & $-2.09^{* *}$ & -1.13 & 0.32 \\
\hline
\end{tabular}

The symbols ${ }^{* *}$ and ${ }^{*}$ correspond, respectively, to a significance level of $5 \%$ and $10 \%$.

TABLE 15: Impact of better-than-expected news on EMEA countries.

\begin{tabular}{|c|c|c|c|c|c|c|c|}
\hline \multirow{2}{*}{$\begin{array}{l}\text { EMEA } \\
\text { Test/event window }\end{array}$} & \multicolumn{7}{|c|}{ Better-than-expected news } \\
\hline & Caasc & $t$-test & Adjusted Patell test & BMP test & Generalized sign test & Skewed-adjusted test & Bootstrap $p$ value \\
\hline$[-20 ; 20]$ & -141 bps & -0.20 & 0.19 & 0.36 & $4.57^{* * *}$ & $2.24^{* *}$ & $0.03^{* *}$ \\
\hline$[-1 ; 1]$ & $-361 \mathrm{bps}$ & $-1.86^{* *}$ & -1.47 & $-1.89^{*}$ & -1.38 & 1.54 & 0.15 \\
\hline$[0 ; 0]$ & -75 bps & -0.67 & -0.92 & -1.00 & $-2.59^{* * *}$ & $1.80^{*}$ & 0.11 \\
\hline
\end{tabular}

The symbols ${ }^{* * *},{ }^{* *}$, and ${ }^{*}$ correspond, respectively, to a significance level of $1 \%, 5 \%$, and $10 \%$.

TABLE 16: Impact of worse-than-expected news on EMEA countries.

\begin{tabular}{|c|c|c|c|c|c|c|c|}
\hline \multirow{2}{*}{$\begin{array}{l}\text { EMEA } \\
\text { Test/event window }\end{array}$} & \multicolumn{7}{|c|}{ Worse-than-expected news } \\
\hline & Caasc & $t$-test & Adjusted Patell test & BMP test & Generalized sign test & Skewed-adjusted test & Bootstrap $p$ value \\
\hline$[-20 ; 20]$ & $-191 \mathrm{bps}$ & -0.26 & 0.15 & 0.29 & $4.44^{* * *}$ & $2.21^{* *}$ & $0.03^{* *}$ \\
\hline$[-1 ; 1]$ & $-352 \mathrm{bps}$ & $-1.80^{*}$ & -1.43 & $-1.84^{*}$ & -1.31 & $1.67^{*}$ & 0.12 \\
\hline$[0 ; 0]$ & -74 bps & -0.65 & 0.87 & -0.94 & $-2.61^{* * *}$ & $1.84^{*}$ & $0.09^{*}$ \\
\hline
\end{tabular}

The symbols ${ }^{* * *},{ }^{* *}$, and * correspond, respectively, to a significance level of $1 \%, 5 \%$, and $10 \%$.

TABLE 17: Impact of better-than-expected news on American countries.

\begin{tabular}{lccccccc}
\hline $\begin{array}{l}\text { Americas } \\
\text { Test/event window }\end{array}$ & Caasc & $t$-test & Adjusted Patell test & BMP test & Generalized sign test & Skewed-adjusted test & Bootstrap $p$ value \\
\hline$[-20 ; 20]$ & +70 bps & 0.54 & $2.64^{* * *}$ & $1.74^{*}$ & -1.10 & $1.91^{*}$ & $0.09^{*}$ \\
{$[-1 ; 1]$} & +54 bps & 1.52 & $1.91^{*}$ & 1.55 & 0.12 & $1.80^{*}$ & $0.07^{*}$ \\
{$[0 ; 0]$} & +26 bps & 1.27 & 1.35 & 1.00 & -0.29 & 1.08 & 0.30 \\
\hline
\end{tabular}

The symbols ${ }^{* * *}$ and ${ }^{*}$ correspond, respectively, to a significance level of $1 \%$ and $10 \%$.

4.2.3. Unemployment Rate. Sovereign CDS quotations do not react very strongly to positive unemployment rate news. The effect is not statistically significant in both short and long time intervals. Prices' response to positive expectation/ realisation surprises is akin to negative news because they both cause a drop in the spread levels. The same pattern can be spotted if the entire sample is taken into account.
Moreover, the incorporation of the new information set appears to occur instantaneously with no evidence of price adjustments, as documented by Hull et al. [19]. Since it is unanimously agreed that good surprises lower the risk perception of a country, it is interesting to attribute the same reaction to bad surprises. It is possible to state with a high degree of certainty that the effect is time period-related and 
TABLE 18: Impact of worse-than-expected news on American countries.

\begin{tabular}{lccccccc}
\hline Americas & & \multicolumn{5}{c}{ Worse-than-expected news } \\
Test/event window & Caasc & $t$-test & Adjusted Patell test & BMP test & Generalized sign test & Skewed-adjusted test & Bootstrap $p$ value \\
\hline$[-20 ; 20]$ & $+341 \mathrm{bps}$ & 2.49 & $4.37^{* * *}$ & $3.39^{* * *}$ & $2.64^{* * *}$ & $4.34^{* * *}$ & $0.00^{* * *}$ \\
{$[-1 ; 1]$} & $+33 \mathrm{bps}$ & 0.89 & 1.53 & 1.36 & $2.23^{* *}$ & 1.00 & 0.32 \\
{$[0 ; 0]$} & $+13 \mathrm{bps}$ & 0.63 & 1.61 & 1.47 & 0.98 & 0.60 & 0.54 \\
\hline
\end{tabular}

The symbols ${ }^{* * *}$ and ${ }^{* *}$ correspond, respectively, to a significance level of $1 \%$ and $5 \%$.

TABle 19: Impact of better-than-expected news on Asian Pacific countries.

\begin{tabular}{lccccccc}
\hline $\begin{array}{l}\text { Asia pacific } \\
\text { Test/event window }\end{array}$ & Caasc & $t$-test & Adjusted Patell test & BMP test & Generalized sign test & Skewed-adjusted test & Bootstrap $p$ value \\
\hline$[-20 ; 20]$ & -71 bps & -0.49 & 1.33 & 0.92 & -0.50 & 1.10 & 0.27 \\
{$[-1 ; 1]$} & -28 bps & -0.71 & -0.32 & -0.28 & -0.92 & -0.64 & 0.53 \\
{$[0 ; 0]$} & $+20 \mathrm{bps}$ & 0.88 & 1.13 & 1.11 & 1.21 & 0.98 & 0.36 \\
\hline
\end{tabular}

TABle 20: Impact of worse-than-expected news on Asian Pacific countries.

\begin{tabular}{|c|c|c|c|c|c|c|c|}
\hline \multirow{2}{*}{$\begin{array}{l}\text { Asia pacific } \\
\text { Test/event window }\end{array}$} & \multicolumn{7}{|c|}{ Worse-than-expected news } \\
\hline & Caasc & $t$-test & Adjusted Patell test & BMP test & Generalized sign test & Skewed-adjusted test & Bootstrap $p$ value \\
\hline$[-20 ; 20]$ & +458 bps & $2.64^{* * *}$ & $4.71^{* * *}$ & $3.09^{* * *}$ & $2.83^{* * *}$ & $2.11^{* *}$ & $0.04^{* *}$ \\
\hline$[-1 ; 1]$ & +24 bps & 0.50 & 1.56 & 1.07 & 0.51 & 1.60 & $0.10^{*}$ \\
\hline$[0 ; 0]$ & +11 bps & 0.41 & 0.58 & 0.52 & 2.12 & 0.98 & 0.36 \\
\hline
\end{tabular}

The symbols ${ }^{* *},{ }^{* *}$, and ${ }^{*}$ correspond, respectively, to a significance level of $1 \%, 5 \%$, and $10 \%$.

is mainly caused by other movers' fluctuations that offset our indicator's result. The financial indicators are some of these major movers. Since our study focuses on the period between two financial crises, it is reasonable that monetary policy actions and interest rates news are more valuable for market investors. Furthermore, an increase in the labour market workforce may be perceived as temporary and due to a new injection of money into the economy that is not always considered to be risk-reducing.

4.2.4. Consumer Sentiment. This indicator is based on the consumers' perception of economic health. Amid the indicators that we are taking into account, this is an indicator of better proxies forward-looking factors. Remarkable impacts are observed for good and bad news surprises. Whereas better-than-expected news causes a hike in the CDS prices and the effect only shows up in the $[-20 ; 20]$ event window, driven by a postannouncement drift, a negative news surprise provokes a plunge in the premiums and is quickly incorporated in the price levels. In this case, the price adjustment is observed to occur immediately. Hence, it is reasonably arguable that a weak form of market efficiency holds as publicly available information is well processed into sovereign CDS prices.

4.3. Reaction in Different Regions. The last research question assesses the responsiveness of the single areas in order to understand which macroregions are more sensitive to macroeconomic fundamentals. For each macro area, we investigate both positive and negative surprises' impacts. The test results and their discussion are given in the following. We can see different patterns of responses in different regions. This can be explained by other factors such as commodity including oil markets' impact on CDS spreads, as pointed out by Bouri et al. [24], Bouri et al. [25], and Bouri et al. [26].

4.3.1. Europe, Middle East, and Africa (EMEA). Tables 15 and 16 report the results on EMEA countries. Consistent with the whole sample results, publicising both good and bad macroeconomic fundamentals lowers CDS spreads. In addition to the statistical significance of the 3-day event window for the news indices, we find that CDS premiums experience an overall decrease over the $[-20 ; 20]$ reference period. The impact corresponds to 141 basis points for better-than-expected news and 191 for worse-than-expected news. The reason why CDS premiums drop is explained by Conrad et al. [15]. When a financial system experiences a period of distress, all asset prices tend to react more strongly to positive news than to negative information. Therefore, the effect of bad news is offset by the positive impact. Furthermore, in line with the literature, our results show that good news lowers risk perception in the sovereign market.

The EMEA region has recently undergone a period of general instability that was characterised by sovereign indebtedness. Thus, the sample is split into two subsamples in order to isolate the effect of the sovereign debt crisis and examine not only the impact it had on the sovereign CDS 
market but also if it caused a change in the effectiveness of the macroeconomic fundamentals on asset prices. We extend the first subsample from June 1, 2009, to November 1, 2012. The second subsample is from November 2, 2012, to June 1, 2016.

It is very interesting to note that during the European sovereign debt crisis, none of the indicators in the analysis appear to soar at all because of the abnormal spread changes. The period immediately following the debt crisis is relatively more tranquil, which is confirmed by the fact that the results are entirely different from the previous case. However, better-than-expected news has an increasing effect on the CDS premiums, and this is true for both the event date and the 41-day window.

Overall, we can state with a high degree of certainty that during the debt crisis, CDS quotations were almost unaffected by the four indicators that we take into account, confirming that the risk perception shifted towards more conditioning unconventional indicators such as future growth variables or financial measures. One possible driving force of European CDS premiums may be the unconventional monetary policy (i.e., quantitative easing or QE) implemented by the European central bank, as Kinateder and Wagner [27] found that QE has indeed helped to lower yield spreads for sovereign bonds in the short window.

4.3.2. Americas and Asian Pacific Countries. Central and Latin American (see Tables 17-18) and Asian Pacific countries (see Tables 19-20) are the most affected by the macroeconomic surprises. Since a large part of the sample is composed of developing countries, these results are in line with Hull et al. [19] and Yildirim [28]. The study of the effect of news on emerging markets shows that they tend to react more strongly to macroeconomic fundamentals than to financial indicators. Apart from a lack of better-than-expected news significance on Asian countries, all the other event studies show evidence for both an abnormal cumulative change in the $[-1 ; 1]$ event window and in a slightly longer term.

\section{Conclusion}

In this work, we initially conduct an event study to test the significance of the impact of gross domestic product, consumer price index, unemployment rate, and consumer sentiment announcement on sovereign credit default swap premiums. Then, we investigate the pre- and postannouncement drifts in order to check whether a weak form of market efficiency is verified in the sovereign risk market. We employ an event study methodology that allows us to estimate the magnitude of the news effects over several event windows. The dataset comprises the historical credit default swap data for 18 countries representing three macroregions: EMEA, Americas, and Asia Pacific. The news information set is divided into better- and worse-than-expected news based on the differential between the released value and the economic market consensus.
This study extends the analysis on CDS spreads to date and provides another angle to interpret sovereign CDS premium dynamics to investors. Considering that the set of macroeconomic fundamentals is only one determining level from which it is possible to investigate the news impact and is also highly time varying, we examine the effectiveness of four nonconventional fundamentals on the credit derivative's prices. An alternative approach from the literature is used, as the theory only focuses on forward-looking indicators that are found to account for $65 \%$ of the premiums' changes. The four indicators only reflect the current economic health that may be considered the basis for forecasting. Focusing on these indicators appears to be worthwhile because it allows to check whether the impact of the financial subprime mortgages crisis has led to a turning point in the effect of news in the sovereign risk market. Moreover, we try to provide the investors that further information concerning the behaviour of sovereign CDS prices over a nonconventional economic period featured by the sovereign debt crisis. To the best of our knowledge, there has been no previous report of an event study about the impact of non-forward-looking macroeconomic fundamentals news on sovereign CDS premiums. Very few studies cover the news reaction in the CDS market, and they mainly focus on the spillover effects using regression techniques that appear to be suitable for testing the CDS determinants but are quite limited in the analysis of market efficiency and preand postrelease drifts. Hence, we contribute to the expansion of knowledge of credit default swap prices' behaviour.

Overall, our findings suggest that the macroeconomic announcement reduces the uncertainty of the sovereign CDS market, and the announcements are still quite effective in the generation of abnormal spread changes. Both longer and shorter event windows are helpful for explaining the CDS premiums' reaction because they provide the investors with useful information. In particular, for institutional investors who dominate this market, they need to closely monitor the behavior of CDS prices in their hedging processes and risk dynamics. Our results highlight the fact that the CDS price reaction to bad news should be very carefully interpreted, and their strategy should be time-varying and requires continuous revision.

Many gaps can still be filled concerning this topic. We suggest the extension of the news dataset to include other variables such as current account balance and negative interest rates as well as other variables that we do not include due to the lack of consistent and regular data. Another interesting variable to investigate is the announcement of QE. Based on the results of Kinateder and Wagner [27], QE may lower the CDS in the short window, but its effect in the long run may be ambiguous since on the one hand, it increases the liquidity of market, but on the other hand, it may intensify the anxiety of market if its effect turns out to be limited, as we have observed in the market turbulence in the US in the spring of 2020.

Furthermore, a more accurate selection of the CDS historical prices that may employ further statistical analysis of the countries is recommended. Spillover effects and period-related responses may affect the overall findings. 
Therefore, an analysis in which the domestic effects are isolated from international impulses would be more specific. However, the CDS market is dropping in terms of the notional amount of outstanding contracts, and, therefore, we assume that future investigations will be harder due to a lack of large quantities of data.

\section{Data Availability}

The data required to reproduce these findings cannot be shared at this time as the data also form part of an ongoing study.

\section{Conflicts of Interest}

The authors declare that they have no conflicts of interest.

\section{References}

[1] M. Caporin, L. Pelizzon, F. Ravazzolo, and R. Rigobon, "Measuring sovereign contagion in Europe," Journal of Financial Stability, vol. 34, pp. 150-181, 2018.

[2] T. G. Andersen, T. Bollerslev, F. X. Dieblod, and C. Vega, "Micro effects of macro announcements: real-time price discovery in foreign exchange," The American Economic Review, vol. 93, no. 1, pp. 38-62, 2003.

[3] P. Balduzzi, E. J. Elton, and T. C. Green, "Economic news and bond prices: evidence from the U.S. Treasury market," Journal of Financial and Quantitative Analysis, vol. 36, pp. 523-543, 2001.

[4] R. Beetsma, M. Giuliodori, F. De Jong, and D. Widijanto, "Spread the news: the impact of news on the European sovereign debt markets during the crisis," Journal of International Money and Finance, vol. 34, pp. 83-101, 2013.

[5] J. Andritzky, A. Jobst, S. Nowak, and N. Tamirisa, "Macroeconomic fundamentals, price discovery and volatility dynamics in emerging markets," International Monetary Fund Working Papers, vol. 9, no. 147, pp. 1-30, 2009.

[6] D. Arru, D. Iacovoni, L. Monteforte, and F. M. Pericoli, "EMU sovereign spreads and macroeconomic news," in Public Debt, Global Governance and Economic Dynamism, L. Paganetto, Ed., pp. 343-363, Public Department, Global Governance and Economic Dynamism, Springer, Berlin, Germany, 2013.

[7] A. Kurov and R. Stan, "Monetary policy uncertainty and the market reaction to macroeconomic news," Journal of Banking and Finance, vol. 86, pp. 127-142, 2018.

[8] E. B. Vrugt, "The return, volatility and interaction of stock and bond markets around macroeconomic announcements," Working paper, 2010.

[9] F. F. Heinz and Y. Sun, "Sovereign CDS spreads in Europe - the role of global risk aversion, economic fundamentals, liquidity, and spillovers," International Monetary Fund Working Papers, vol. 14, no. 17, 2014.

[10] T. Chebbi and M. Sarraj, "News and sovereign CDS markets: evidence from the euro area," International Journal of Bonds and Derivatives, vol. 3, no. 4, pp. 320-334, 2017.

[11] F. A. Longstaff, J. Pan, L. H. Pedersen, and K. J. Singleton, "How sovereign is sovereign credit risk?" American Economic Journal: Macroeconomics, vol. 3, no. 2, pp. 75-103, 2011.

[12] P. K. Narayan and D. Bannigidadmath, "Financial news and CDS spreads," Journal of Behavioral and Experimental Finance, vol. 29, Article ID 100448, 2021.
[13] C. Greatrex, "The credit default swap market's reaction to earnings announcements," Journal of Applied Finance, vol. 19, pp. 193-216, 2009.

[14] S. J. Kim, L. Salem, and E. Wu, "The role of macroeconomic news in sovereign CDS markets: domestic and spillover news effects from the U.S., the Eurozone and China," Journal of Financial Stability, vol. 18, pp. 208-224, 2015.

[15] J. Conrad, B. Cornell, and W. R. Landsman, "When is bad news really bad news?" Journal of Finance, vol. 57, pp. 2507-2532, 2002.

[16] M. Ehrmann, G. Gaballo, P. Hoffmann, and G. Strasser, "Can more public information raise uncertainty? The international evidence on forward guidance," Journal of Monetary Economicsvol. 108, pp. 93-112, 2019.

[17] C. Andres, A. Betzer, and M. Doumet, "Measuring abnormal credit default swap spreads," Global Finance Journal, Working Paper, 2016.

[18] H. Bouzgarrou and T. Chebbi, "The reaction of sovereign CDS spread volatilities to news announcements," Journal of Asset Management, vol. 17, no. 5, pp. 347-360, 2016.

[19] J. Hull, M. Predescu, and A. White, "The relationship between credit default swap spreads, bond yields, and credit rating announcements," Journal of Banking and Finance, vol. 28, no. 11, pp. 2789-2811, 2004.

[20] L. Goldberg and D. Leonard, "What moves sovereign bond markets? The effects of economic news on U.S. and German yields," Current Issues in Economics and Finance, vol. 9, no. 9, pp. 1-7, 2003.

[21] A. C. MacKinlay, "Event studies in economics and finance," Journal of Economic Literature, vol. 35, no. 1, pp. 13-39, 1997.

[22] B. M. Barber, J. D. Lyon, and C. L. Tsai, "Improved methods of long-run abnormal stock returns," Journal of Finance, vol. 54, pp. 165-201, 1999.

[23] F. Wilcoxon, "Individual comparisons by ranking methods," Biometrics Bulletin, vol. 1, no. 6, pp. 80-83, 1945.

[24] E. Bouri, M. E. de Boyrie, and I. Pavlova, "Volatility transmission from commodity markets to sovereign CDS spreads in emerging and frontier countries," International Review of Financial Analysis, vol. 49, pp. 155-165, 2017.

[25] E. Bouri, N. Jalkh, and D. Roubaud, "Commodity volatility shocks and BRIC sovereign risk: a GARCH-quantile approach," Resources Policy, vol. 61, pp. 385-392, 2019.

[26] E. Bouri, I. Kachacha, and D. Roubaud, "Oil market conditions and sovereign risk in MENA oil exporters and importers," Energy Policy, vol. 137, Article ID 111073, 2020.

[27] H. Kinateder and N. Wagner, "Quantitative easing and the pricing of EMU sovereign debt," The Quarterly Review of Economics and Finance, vol. 66, pp. 1-12, 2017.

[28] Z. Yildirim, "Global financial conditions and asset markets: evidence from fragile emerging economies," Economic Modelling, vol. 57, pp. 208-220, 2016. 